\title{
Can the Score for Neonatal Acute Physiology II (SNAPII) Predict Morbidity and Mortality in Neonates with Sepsis?
}

Nahed Fahmy Helal ${ }^{1}$, Nashwa Mamdouh Samra², Eman Abdel Ghany Abdel Ghany ${ }^{1 *}$ and Ebtehal Adel Said ${ }^{2}$

${ }^{1}$ Department of Pediatrics, Cairo University, Egypt

${ }^{2}$ Department of Pediatrics, Fayoum University, Egypt

\section{Abstract}

Objective: We investigated whether Score For Neonatal Acute Physiology II (SNAP II) score can predict mortality and or Organ Dysfunction (OD) in neonatal sepsis.

Methods: Eighty Egyptian newborns hospitalized for neonatal sepsis were investigated through a multicenter observational prospective study to determine whether SNAP II applied in the $1^{\text {st }} 12$ hours of admission would predict mortality and or OD.

Results: The median SNAP II was significantly higher in babies who died or developed OD versus those who survived and improved $(P=0.003$ and $P=0.001$ respectively). Individual parameters of the SNAP II didn't contribute equally to the risk of death, low mean arterial blood pressure and lowest blood $\mathrm{pH}$ were significantly associated with $\mathrm{OD}$ and death $(P=0.002)$. ROC curves for the SNAP II score $\geq 40$ showed moderate predictive accuracy and $90.4 \%$ and $88.9 \%$ sensitivity for OD and death, respectively.

Conclusion: SNAP II score can predict mortality and OD in neonatal sepsis.

Keywords: SNAP II; Neonate; Sepsis; Organ dysfunction; Mortality

\section{Introduction}

Neonatal sepsis is a worldwide public health issue in which marked variations concerning its risk and prognostic factors have been reported [1]. Neonatal sepsis is a common life threatening disease with an incidence of 3.5 to 8 cases per 1,000 live births and mortality rate of 16 to $30 \%$ [2], causing about 1.6 million deaths annually in developing countries [3]. Neonatal illness severity scoring systems assess the severity of illness in terms of degree of derangement from normal physiology across a number of physical examination findings and laboratory test results.

The SNAP score (developed and mainly used in the United States and Canada) is used for describing populations, stratifying risk in epidemiologic and clinical trials and projecting resource utilization. It is based on 28 variables obtained during the first 24 hours after admission with each parameter weighted according to expert opinion, with a score of $0,1,3$ or 5 assigned to each variable [4].

In 2001, Richardson et al. [5] developed and validated SNAP II score reducing the number of evaluated items to six (mean blood pressure, lowest temperature, $\mathrm{PO}_{2} / \mathrm{FiO}_{2}$ ratio, serum $\mathrm{pH}$, multiple seizures, and urine output), in order to facilitate utilization of the system and the period of data collection to 12 hours.

Previous studies have applied SNAP II as a measure of illness severity in mechanically ventilated term babies and to predict short term adverse respiratory outcomes in newborns 34 weeks gestation admitted to the neonatal intensive care unit (NICU) [6-8]. Many babies may not be very sick at admission to NICU and may develop severe sickness later in the course of NICU stay. Hence, we applied SNAP II to the diagnosis of septicemia in babies already admitted in the NICU and we observed them for 14 days for their outcomes.

A recent Indian study [9] has attempted to use SNAP II parameters as prognostic markers among neonates after the onset of sickness in the NICU. This study is a novel Egyptian work that aimed to investigate whether SNAP II score applied in the $1^{\text {st }} 12$ hours of admission can predict mortality and or Organ Dysfunction (OD) in neonates with septicemia and to determine the contribution of the individual parameters of SNAP II score to the risk of OD and death.

\section{Methods}

This was an observational prospective study which included 80 newly admitted neonates with neonatal sepsis at the NICUs of Fayoum University Hospital (Fayoum Governorate), El Mounira Cairo University Children Hospital and Al-Kasr Al-Aini hospital (Cairo Governorate) over a period of 6 months starting from June 2012 to November 2012. Approval of Research Committee of Pediatric Units was obtained. Data confidentiality was preserved according to the Revised Helsinki Declaration of Bioethics [10].

Our inclusion criteria were preterm and term neonates of both gender with clinical and/or laboratory signs consistent with neonatal sepsis. Gestational age was confirmed by new Ballard score [11]. Neonates with major congenital anomalies, those with genetic disorders and neonates with surgical conditions were excluded from the study. Babies were observed till day 14 of admission.

We termed sepsis as a suspected or confirmed infection in the presence of Systemic Inflammatory Response Syndrome (SIRS). This meant a newborn must have a positive blood culture and fulfill at least 2 of the 4 SIRS criteria (in reference to the study Sundaram et al. [9]).

- Core temperature $>38.5$ or $<36.0^{\circ} \mathrm{C}$

*Corresponding author: Eman Abdel Ghany Abdel Ghany, Assistant Professo of Pediatrics, New Children Hospital (Abu El Rish), Cairo University Hospitals Ali Basha Ebrahim, PO Box 11562, Cairo, Egypt, Tel: +2 01223773197; E-mail: dreman75@yahoo.com

Received October 27, 2013; Accepted November 22, 2013; Published November 24, 2013

Citation: Helal NF, Samra NM, Abdel Ghany EAG, Said EA (2013) Can the Score for Neonatal Acute Physiology II (SNAPII) Predict Morbidity and Mortality in Neonates with Sepsis? J Neonatal Biol 2: 121. doi:10.4172/2167-0897.1000121

Copyright: @ 2013 Helal NF, et al. This is an open-access article distributed under the terms of the Creative Commons Attribution License, which permits unrestricted use, distribution, and reproduction in any medium, provided the original author and source are credited. 
- Tachycardia, defined as a mean heart rate $>2 \mathrm{SD}$ above normal for age, and bradycardia, defined as a mean heart rate $<10^{\text {th }}$ percentile for age.

- Mean respiratory rate $>2 \mathrm{SD}$ above normal for age.

- Leukocyte count elevated or depressed for age or $>10 \%$ immature neutrophils.

And or those with at least one organ dysfunction [12].

Confirmatory tests were done using the practical sepsis screen [13] .The screen is considered positive if any two or more of these tests were abnormal: Total leukocyte count is $<5000$ or $>20000 / \mathrm{mm}^{3}$, low absolute neutrophil counts as per Manroe chart [14] for term and Mouzinho's chart [15] for very low birth weight infants, immature/total neutrophil $>0.2$, Micro-ESR $>15 \mathrm{~mm}$ in 1 st hour and $\mathrm{C}$ reactive protein $(\mathrm{CRP})>10$ $\mathrm{mg} / \mathrm{L}$.

We diagnosed OD according to the criteria of Goldstein et al. [12].

Coagulation profile was done in patients suspected with disseminated intravascular coagulation (DIC) including International Normalized Ratio (INR), activated partial thromboplastin time (APTT) and platelet count.

Blood chemistry included: $\mathrm{Na}^{+}, \mathrm{K}^{+}, \mathrm{Ca}^{+2}$ (total and ionized), kidney function tests, liver function tests, arterial blood gases and others as required to detect $\mathrm{OD}$.

SNAP II [9] was applied on all our septic neonates in the $1^{\text {st }} 12$ hours of admission.

Variables of SNAP II score are shown in table 1.

\section{Interpretation of SNAP II score}

Severity of the illness was arbitrarily graded according to the SNAP II score as follows: mild: $1-20$, moderate: $21-40$, severe: $>40$.

All subjects were followed up to a maximum of 14 days to detect their outcome (improvement, OD or death).

\section{Statistical analysis}

Data management and analysis were performed using Statistical

\begin{tabular}{|c|c|c|}
\hline VARIABLES & VALUES & POINTS \\
\hline \multirow{3}{*}{ Mean blood pressure } & $\geq 30 \mathrm{mmHg}$ & 0 \\
\hline & $20-29 \mathrm{mmHg}$ & 9 \\
\hline & $<20 \mathrm{mmHg}$ & 19 \\
\hline \multirow{3}{*}{ Temperature } & $>35.6^{\circ} \mathrm{C}$ & 0 \\
\hline & $35-35.6^{\circ} \mathrm{C}$ & 8 \\
\hline & $<35^{\circ} \mathrm{C}$ & 15 \\
\hline \multirow{4}{*}{$\mathrm{PO}_{2}(\mathrm{mmHg}) / \mathrm{FiO}_{2}(\%)$} & $>2.49$ & 0 \\
\hline & $1.0-2.49$ & 5 \\
\hline & $0.3-0.99$ & 16 \\
\hline & $<0.3$ & 28 \\
\hline \multirow{3}{*}{ Lowest serum $\mathrm{pH}$} & $\geq 7.2$ & 0 \\
\hline & 7.1-7.19 & 7 \\
\hline & $<7.1$ & 16 \\
\hline \multirow{2}{*}{ Multiple seizures } & No & 0 \\
\hline & Yes & 19 \\
\hline \multirow{3}{*}{ Urine output(ml/kg/h) } & $\geq 1$ & 0 \\
\hline & $0.1-0.9$ & 5 \\
\hline & $<0.1$ & 18 \\
\hline
\end{tabular}

Table 1: Variables of SNAP-II:

$\left(\mathrm{FiO}_{2}\right)$ : Fraction of inspired Oxygen.

\begin{tabular}{|l|c|c|}
\hline Initial diagnoses & $\begin{array}{c}\text { Number of } \\
\text { patients }\end{array}$ & $\begin{array}{c}\text { Percentage } \\
\text { (\%) }\end{array}$ \\
\hline Respiratory distress syndrome (RDS) & 24 & 30.0 \\
\hline Pneumonia & 10 & 12.5 \\
\hline Preterm neonates (PT) & 10 & 12.5 \\
\hline Hypoxic ischemic encephalopathy (HIE) & 6 & 7.5 \\
\hline Jaundice & 4 & 5.0 \\
\hline Neonatal convulsions & 4 & 5.0 \\
\hline Non specific manifistations & 4 & 5.0 \\
\hline Cholestasis & 3 & 3.8 \\
\hline Acute bilirubin encephalopathy & 2 & 2.5 \\
\hline Hemorrhagic disease of newborn & 2 & 2.5 \\
\hline Intracranial hemorrhage (ICH) & 2 & 2.5 \\
\hline Inborn error of metabolism & 2 & 2.5 \\
\hline Meconium aspiration syndrome (MAS) & 2 & 2.5 \\
\hline CNS infection & 1 & 1.3 \\
\hline Congenital heart disease & 1 & 1.3 \\
\hline Necrotizing enterocolitis (NEC) & 1 & 1.3 \\
\hline Neck abscess & 1 & 1.3 \\
\hline Transient tachypnea of newborn (TTN) & 1 & 1.3 \\
\hline Total & 80 & 100.0 \\
\hline
\end{tabular}

Table 2: Initial diagnoses of enrolled neonates.

\begin{tabular}{|l|c|}
\hline Organism & Number (\%) \\
\hline coagulase-ve Staphylococci & $8(10)$ \\
\hline Pseudomonas & $6(7.50)$ \\
\hline Acinetobacter & $5(6.25)$ \\
\hline Klebsiella & $2(2.50)$ \\
\hline Enterobacter & $1(1.25)$ \\
\hline E.coli & $1(1.25)$ \\
\hline
\end{tabular}

Table 3: Distribution of organisms in blood culture.

Analysis Systems. The graphs were done using Microsoft Word.

Numerical data were summarized using means and standard deviations or median and ranges. Categorical data were summarized as percentages. Comparisons between two groups with respect to numeric variables were done by Mann-Whitney test, a nonparametric test equivalent to the Student's $t$ test. The Kruskal-Wallis test, a nonparametric test equivalent to analysis of variance was used to compare more than 2 groups. Comparisons between categorical data were done using the chi-square test or the Fisher's exact test for small sample size. The Receiver-Operator Characteristic (ROC) curve was used to display the relationship between sensitivity and specificity [16]. All $P$-values were two-sided. $P$-values $<0.05$ were considered significant.

\section{Results}

The initial diagnoses associated with neonatal sepsis were as following: $24(30 \%)$ neonates presented with respiratory distress syndrome, $10(12.5 \%)$ patients with confirmed pneumonia, and 10 (12.5\%) newborns were admitted because of prematurity. (The other diagnoses are listed in table 2).

Neonates were as follow: number of neonates with early onset sepsis (EOS) was $33(41.3 \%)$ and in those with late onset sepsis (LOS) was $47(58.8 \%)$. Forty three (53.8\%) neonates were boys and 37 (46.3\%) were girls. The mean gestational age of the enrolled neonates was 34.95 weeks (28-40 weeks). The mean weight on admission was $2.32 \mathrm{Kg}$ (1$3.5 \mathrm{Kg}$ ). The median of day of onset of illness was 3.5 days (1-28 days).

Blood culture was positive in $23(28.75 \%)$ neonates and sepsis screen was positive in $73(91.3 \%)$ neonates. All culture negative subjects 
had a positive sepsis screen. The most common causative organism was coagulase negative Staphylococci (10\%) (Table 3).

Twenty seven (33.8\%) neonates died within the 14-days observation period due to septicemia, while 35 (43.8\%) babies had organ dysfunction. Ten (12.5\%) babies had improved OD and $25(31.3 \%)$ babies had persistent OD.

The study population had a median SNAP II score of 12.5 (IQR 032 ) at enrollment. Forty six (57.7\%) neonates had mild illness [SNAP II=1-20], 22 (27.5\%) had moderate illness [SNAP II=21-40] and 12 $(14.8 \%)$ had severe illness [SNAP II $>40]$.

In term babies median SNAP II score was 19 (IQR 0-65) versus 12 (IQR 0-60) in preterm babies; $\mathrm{P}$ value $=0.476$.

The median SNAP II score in very low birth weight (VLBW) babies was 12 (IQR 0-32), in low birth weight (LBW) babies it was 12.5 (IQR $0-60$ ) and in appropriate for gestational age babies (AGA) it was 19 (IQR 0-65) with; $\mathrm{P}$ value $=0.71$.

The death percentage by SNAP II category was $21.7 \%$ for mild illness, $40.9 \%$ for moderate illness and $66.7 \%$ for severe illness, as shown in table 4.

The median number of organs with dysfunction involved during the 14 days observation period was 2 (IQR 1-3). In 10 (12.5\%) babies, OD improved by day 14 .

Respiratory system was the most frequently involved organ at enrollment as $27(33.8 \%)$ neonates presented with respiratory distress syndrome and pneumonia, followed by the hematologic system $(30 \%)$ with 9 (11.3\%) babies had (DIC). Seventeen (21.3\%) babies had cardiovascular involvement. Shock requiring vasoactive drug support was present in $16(20 \%)$ babies and renal failure was diagnosed in 8 (10\%) babies at enrollment.

There was a significant difference in the median SNAP II in babies with persistent OD; it was 21 (IQR 11-36) versus 12 (IQR 0-37.5) in those with improving or normalized OD; $P=0.001$.

When the individual SNAP-II parameters were analyzed, it was found that parameters related to perfusion (mean arterial pressure

\begin{tabular}{|c|c|c|c|c|}
\hline $\begin{array}{l}\text { SNAP II score } \\
\text { category }\end{array}$ & $\begin{array}{c}\text { Alive }(n=), \\
(\%)\end{array}$ & $\begin{array}{c}\text { Death }(n=), \\
(\%)\end{array}$ & $\begin{array}{c}\text { Total number, } \\
\text { (\%) }\end{array}$ & $\begin{array}{c}\text { Overall } P \\
\text { value }\end{array}$ \\
\hline Mild (1-20) & $36(78.3 \%)$ & $10(21.7 \%)$ & $46(100.0 \%)$ & \multirow{4}{*}{ **0.001 } \\
\hline Moderate (21-40) & $13(59.1 \%)$ & $9(40.9 \%)$ & $22(100.0 \%)$ & \\
\hline Severe $(>40)$ & $4(33.3 \%)$ & $8(66.7 \%)$ & $12(100.0 \%)$ & \\
\hline Total & 53 (66.3\%) & 27 (33.8\%) & 80 (100.0\%) & \\
\hline
\end{tabular}

${ }^{* *} P$ value $<0.05$ is considered significant.

Table 4: The relationship between death percentage of studied babies and SNAP II category.

\begin{tabular}{|l|c|c|c|c|c|}
\hline Parameters & $\begin{array}{c}\text { Improved } \\
\text { and } \\
\text { discharged } \\
(\mathbf{n = 1 8 )}\end{array}$ & $\begin{array}{c}\text { Improved } \\
\text { OD }(\mathbf{n = 1 0})\end{array}$ & $\begin{array}{c}\text { Persistent } \\
\text { OD }(\mathbf{n = 2 5})\end{array}$ & $\begin{array}{c}\text { Died } \\
(\mathbf{n = 2 7})\end{array}$ & P value \\
\hline $\mathrm{MAP} \leq 29 \mathrm{mmHg}$ & 0 & 3 & 8 & 8 & 0.064 \\
\hline Lowest blood $\mathrm{pH}(<7.20)$ & 1 & 5 & 12 & 17 & $* * 0.002$ \\
\hline $\mathrm{PaO}_{2} / \mathrm{FiO}_{2}$ ratio $(<2.50)$ & 2 & 4 & 20 & 22 & ${ }^{* *}<0.001$ \\
\hline Urine output $(<1 \mathrm{~mL} / \mathrm{kg} / \mathrm{hr})$ & 1 & 1 & 4 & 8 & 0.175 \\
\hline $\begin{array}{l}\text { Lowest } \\
\text { temperature }\left(35.6^{\circ} \mathrm{C}\right)\end{array}$ & 0 & 0 & 1 & 2 & $\#$ \\
\hline Multiple seizures & 1 & 2 & 8 & 10 & 0.101 \\
\hline
\end{tabular}

${ }^{* *} P$ value $<0.05$ is significant

"Number of study subjects with hypothermia was too small for valid analysis Table 5: Individual SNAP I| parameters and outcome.

\begin{tabular}{|c|c|c|c|c|}
\hline \multirow[t]{2}{*}{ Measurement } & \multicolumn{2}{|c|}{$O D$} & \multicolumn{2}{|c|}{ Death } \\
\hline & $\%$ & $(95 \% \mathrm{Cl})$ & $\%$ & $(95 \% \mathrm{Cl})$ \\
\hline Sensitivity & 23.1 & $11.2-34.9$ & 29.6 & $11.2-48.0$ \\
\hline Specificity & 100 & --- & 92.5 & $85.1-99.8$ \\
\hline Positive predictive value (PPV) & 100 & --- & 66.7 & $35.4-98.0$ \\
\hline Negative predictive value (NPV) & 41.2 & $29.2-53.2$ & 72.1 & $61.1-83.0$ \\
\hline
\end{tabular}

Table 6: SNAP I| score more than 40 as a prognostic test for death and organ dysfunction.

\section{ROC Curve}

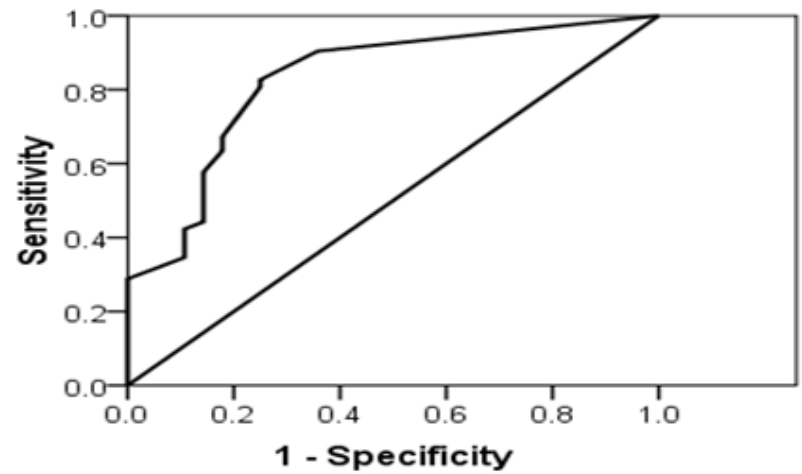

Figure 1: ROC curve for SNAP II as a predictor of OD in neonates with sepsis.

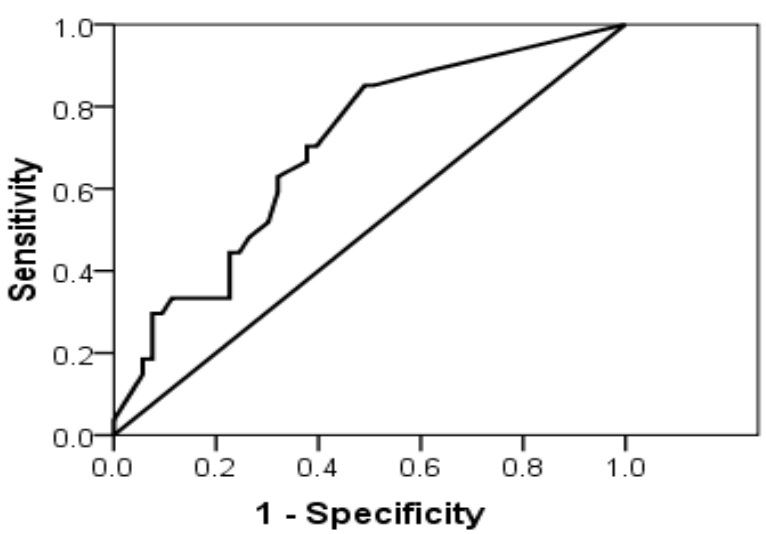

Figure 2: ROC curve for SNAP II as a predictor of death in neonates with sepsis.

and acidosis) were significantly associated with death as well as organ dysfunction at day 14 as shown in table 5 .

Table 6 shows the sensitivity, the specificity and the predictive values of SNAP II score greater than 40 in the prognosis of neonatal sepsis.

The area under the (ROC) curve for SNAP II and OD was 0.829 (95\% CI 0.731-0.926), as shown in figure 1. While the area under the (ROC) curve for SNAP II and death was 0.699 (95\% CI 0.58-0.818), as shown in figure 2 .

\section{Discussion}

The study of illness severity and mortality risk measurement 
among newborns admitted to NICUs is attaining an increasing level of importance. In order to compare mortality levels of different NICUs, even after making adjustments for factors such as gender, birth weight, gestational age and ethnicity, it is still necessary for subject disease severity to be similar [17].

Given the median SNAP II score in our study was lower than that described by Sundaram et al. [9] (12.5 versus 37), we attribute this finding to their inclusion criteria of only severely septic neonates.

We found that the median SNAP II was significantly higher in the babies who died $(n=27)$ compared to those who survived $(n=53)$. These results were similar to the results of Sundaram and his colleagues [9] who noticed a significantly higher median SNAP II in babies who died versus in those who survived [median (IQR) 43 (36-53.5) vs. 18 (1637 ), respectively; $P<0.001$ ].

Maiya et al. [18] had reported the mean SNAP in babies who survived versus who died as 4.88 vs. $17.38(\mathrm{P}<0.001)$. Sutton et al. [8] and Maiya et al. [18] who used the older generation SNAP in babies at the point of admission to the NICU, being a physiological score of severity of illness found that the higher the score the greater would be the physiologic derangement and the organ involvement.

Consistent with this, we observed higher SNAP II in babies with persisted/worsened organ dysfunction and vice versa. This indicates that organ function recovery was better in babies with a lower severity of illness.

In the current study, we found that respiratory system was the most frequently system involved at enrollment followed by the hematologic system then the cardiovascular system and when the individual SNAP II parameters were analyzed, it was found that parameters related to circulatory instability like low mean arterial pressure and lowest blood $\mathrm{pH}$ were significantly associated with death as well as organ dysfunction at day $14, P=0.002$. Also hypoxemia was significantly observed in babies with persistent $\mathrm{OD}$ and who died vs. those who survived, $P<0.001$.

Regarding hypothermia, the number of babies with hypothermia was too small for valid analysis. Multiple seizures were observed more commonly in babies who died but did not attain statistical significance. These results indicate that individual parameters of the SNAP II did not contribute equally to the risk of death.

When we constructed ROC curves for the SNAP II score $\geq 40$, they showed moderate predictive accuracy. The area under the (ROC) curve was 0.829 with sensitivity (90.4\%) for OD and was 0.699 with sensitivity (88.9\%) for death.

In contrast, Sundaram et al. study [9] had found that the area under the (ROC) curve for SNAP II curve for death was 0.82 (95\% CI 0.68$0.95, \mathrm{P}<0.001)$.

In comparison, Richardson and his colleagues [5] found that in all birth weights, SNAPPE II (Score for Neonatal Acute PhysiologyPerinatal Extension) had excellent discrimination. Area under the (ROC) curve was $0.91 \pm 0.01$. Accordingly SNAP II and SNAPPE II are empirically validated illness severity and mortality risk scores for newborn intensive care. .

The strengths of our study are: SNAP II is a simple, objective and physiology-based measure of illness severity that is relatively easy to obtain. The six items in SNAP II are readily available in neonatal medical records and a score can be assessed in 4 to 6 minutes. An easily calculated illness severity score can be used by clinicians to predict patient outcomes and resource use.
A limitation of this study is the limited number of neonates. The score was applied on 80 patients with neonatal sepsis associated with different primary diagnoses and different severity stages of sepsis.

\section{Conclusion}

SNAP II $\geq 40$ can predict OD and death with moderate predictive accuracy when applied on admission to neonates with sepsis. Parameters related to perfusion (mean arterial pressure and acidosis) were significantly associated with death as well as organ dysfunction at day 14 .

From the results of the present study, we recommend application of the score on neonates on the first day of admission and serially in different institutions that may be helpful in making comparison between hospitals for outcomes of admitted neonates.

\section{Acknowledgement}

We would like to express our appreciations to colleagues and nurses in the Neonatology unit.

\section{References}

1. Leal YA, Álvarez-Nemegyei J, Velázquez JR, Rosado-Quiab U, DiegoRodríguez N, et al. (2012) Risk factors and prognosis for neonatal sepsis in southeastern Mexico: analysis of a four-year historic cohort follow-up. BMC Pregnancy Childbirth 12: 48.

2. Martin GS, Mannino DM, Eaton S, Moss M (2003) The epidemiology of sepsis in the United States from 1979 through 2000. N Engl J Med 348: 1546-1554.

3. Vergnano S, Sharland M, Kazembe P, Mwansambo C, Heath PT (2005) Neonatal sepsis: an international perspective. Arch Dis Child Fetal Neonatal Ed 90: F220-224.

4. Richardson DK, Gray JE, McCormick MC, Workman K, Goldmann DA (1993) Score for Neonatal Acute Physiology: a physiologic severity index for neonatal intensive care. Pediatrics 91: 617-623

5. Richardson DK, Corcoran JD, Escobar GJ, Lee SK (2001) SNAP-II and SNAPPE-II: Simplified newborn illness severity and mortality risk scores. J Pediatr 138: 92-100.

6. Sankaran K, Chien LY, Walker R, Seshia M, Ohlsson A; Canadian Neonata Network (2002) Variations in mortality rates among Canadian neonatal intensive care units. CMAJ 166: 173-178.

7. Escobar GJ, Shaheen SM, Breed EM, Botas C, Greene JD, et al. (2004) Richardson score predicts short-term adverse respiratory outcomes in newborns $>/=34$ weeks gestation. J Pediatr 145: 754-760.

8. Sutton L, Bajuk B, Berry G, Sayer GP, Richardson V, et al. (2002) Score of neonatal acute physiology as a measure of illness severity in mechanically ventilated term babies. Acta Paediatr 91: 415-423.

9. Sundaram V, Dutta S, Ahluwalia J, Narang A (2009) Score for neonatal acute physiology II predicts mortality and persistent organ dysfunction in neonates with severe septicemia. Indian Pediatr 46: 775-780.

10. World Medical Association (2008) Declaration of Helsinki Ethical Principles for Medical Research Involving Human Subjects. the 59th WMA Genera Assembly, Seoul, South Korea.

11. Ballard JL, Khoury JC, Wedig K, Wang L, Eilers-Walsman BL, et al. (1991) New Ballard Score, expanded to include extremely premature infants. J Pediatr 119: 417-423.

12. Goldstein B, Giroir B, Randolph A; International Consensus Conference on Pediatric Sepsis (2005) International pediatric sepsis consensus conference: definitions for sepsis and organ dysfunction in pediatrics. Pediatr Crit Care Med 6: 2-8.

13. Polinski C (1996) The value of the white blood cell count and differential in the prediction of neonatal sepsis. Neonatal Netw 15: 13-23.

14. Manroe BL, Weinberg AG, Rosenfeld CR, Browne R (1979) The neonatal blood count in health and disease. I. Reference values for neutrophilic cells. J Pediatr 95: 89-98.

15. Manzoni P, Rinaldi M, Cattani S, Pugni L, Romeo MG, et al. (2009) Bovine 
Citation: Helal NF, Samra NM, Abdel Ghany EAG, Said EA (2013) Can the Score for Neonatal Acute Physiology II (SNAPII) Predict Morbidity and Mortality in Neonates with Sepsis? J Neonatal Biol 2: 121. doi:10.4172/2167-0897.1000121

Pge 5 of 5

lactoferrin supplementation for prevention of late-onset sepsis in very low-birthweight neonates: a randomized trial. JAMA 302: 1421-1428.

16. Dawson B, Trapp GT (2001) Basic and Clinical Biostatistics (3rdedtn) Lange medical book, Appleton \& Lange, Norwalk, Connecticut.
17. Richardson DK, Phibbs CS, Gray JE, McCormick MC, Workman-Daniels K, et al. (1993) Birth weight and illness severity: independent predictors of neonatal mortality. Pediatrics 91: 969-975.

18. Maiya PP, Nagashree S, Shaik MS (2001) Role of score for neonatal acute physiology (SNAP) in predicting neonatal mortality. Indian J Pediatr 68: 829834. 